\title{
Integrating Agile Development Processes and User Centred Design- A Place for Usability Maturity Models?
}

\author{
Dina Salah, Richard Paige, and Paul Cairns \\ Department of Computer Science, \\ University of York, York, UK \\ \{dm560, richard.paige, paul. cairns\}@york.ac.uk
}

\begin{abstract}
The aim of this paper is to explore and evaluate the role that can be played by Usability Maturity Models (UMMs) in integrating agile processes and User Centred Design (UCD). UMMs can be utilised in Agile projects as a diagnostic tool to assess the extent to which UCD is systematically and consistently implemented and the extent of effective implementation of UCD in development projects. This paper investigated the suitability of Nielsen Corporate Usability Maturity Model for utilisation in the Agile domain in order to assess the organisation's UCD capability. It reported on applying Nielsen Model in five case studies that performed Agile and User Centred Design Integration (AUCDI) and utilising the model in assessing their usability maturity level. The results revealed the existence of a correlation between the success of AUCDI attempts and the AUCDI case study's usability maturity level. These results can have positive implications on AUCDI practice since practitioners who aim to achieve the integration can utilise Nielsen model to identify their strengths and weaknesses in regards to UCD related aspects and accordingly plan for improvement.
\end{abstract}

Keywords: Agile Software Development Processes, User Centred Design, Agile User Centred Design Integration, Usability Maturity Models, Maturity Models.

\section{Introduction}

Agile methods are lightweight software development methods that tackle perceived limitations of plan-driven methods via a compromise between absence of a process and excessive process [13. Agile processes aim to deal with volatile requirements via discarding upfront, precisely defined plans. They are iterative and are used to develop software incrementally. Different Agile processes implement these ideas in different ways. All Agile processes share common values and principles, defined in the Agile Manifesto [1].

User Centred Design (UCD) is a set of techniques, methods, procedures and processes as well as a philosophy that places the user at the centre of the 
development process in a meaningful, appropriate and rigourous ways [15]6]. The goal of applying UCD is to attempt to satisfy users via producing usable and understandable products that meet their needs and interests [6] in addition to their goals, context of use, abilities and limitations [2]. The usability of a product is the consequence of systematic UCD work that occurs throughout the development process and continues even after product release in order to enhance subsequent versions 6.

Maturity Models are normative [17] reference models that embrace the assumption of predictable evolution and change patterns. The main purpose of maturity models is to assess the current situation in order to evaluate the strengths and weaknesses and then prioritize and plan for improvement [17. This is achieved via evolutionary successive stages or levels that signify step by step patterns of evolution and change designating the desirable or current organisational capabilities against a specific class of entities [28,1425].

Improving the effectiveness of user-centred design in software development is a considerable challenge in many organisations. Usability Maturity Models (UMMs) were proposed to conduct a status-quo analysis of UCD. UMMs aim to assist organisations in conducting a systematic analysis that evaluates the strengths and weaknesses of the organisation in regards to UCD related aspects [19] and accordingly plan for improvement actions [21]. Usability Capabiliy is defined as

A characteristic of a development organisation that determines its ability to consistently develop products with high and competitive level of usability [21].

This paper provides details of an exploratory study for the role that could be played by usability maturity models in the domain of integrating agile development processes and user centred design. The rest of this paper is structured as follows: section 2 provides a background on agile and user centred design integration. Section 3 discusses the research approach. Section 4 provides details of the utilisation of Nielsen Corporate Usability Maturity Model in five AUCDI Case Studies. Section 5 discusses the results and section 6 discusses the conclusion and future work.

\section{Agile Development Processes and User Centred Design Integration}

Agile development processes and User Centred Design integration have been gaining increased interest. This interest in AUCDI is arguably due to three reasons: first, the reported advantages of UCD on the developed software as it enables developers to understand the needs of the potential users of their software, and how their goals and activities can be best supported by the software thus leading to improved usability and user satisfaction. Second, none of the major Agile processes explicitly have guidance for how to develop usable software [23. In addition, the interaction design role, usability, and user interface design 
in an Agile team is unclear and largely overlooked [5]3. Furthermore, principles and practices for understanding and eliciting usability and user requirements and evaluating Agile systems for usability and UX are generally considerably deficient 2322 . Third, there appear to be philosophical and principled differences between Agile methods and UCD in focus, evaluation method, culture and documentation that suggest that their integration will be fundamentally challenging.

Although Agile and User Centred Design Integration (AUCDI) research is growing, it has not yet exploited the potential of UMMs, which is strongly relevant to AUCDI practice. A systematic literature review [30] was conducted that included 71 papers on AUCDI that classified AUCDI studies according to the integration approach revealed eight different categories, non of which focused on utilization of UMMs. UMMs can be utilised in the Agile development projects as a diagnostic tool. They can assist in assessing the status quo to evaluate the extent to which UCD is systematically and consistently implemented as well as the extent of effective implementation of UCD in development projects. The results can help organisations identify their strengths and weaknesses in regards to UCD related aspects and accordingly plan for improvement actions.

Thus this study has two aims: first, to investigate the suitability of UMMs for utilisation in the context of Agile projects in order to assess the organisation's UCD capability and/or performance. Second, to investigate the relationship between the success of AUCDI attempts and usability maturity level.

\section{Research Approach}

This section provides details on the research approach that was used to achieve the research aims.

\subsection{Comparative Study of Usability Maturity Models}

The first step of this research involved conducting a comparative study of UMMs in order to choose one of those UMMs for utilisation in assessing the usability maturity level of case studies that integrated Agile development processes and UCD. To the best of our knowledge there exists eleven usability maturity models for which an overview will be provided below. The features, perspective of usability integration, maturity approaches, scope, and documentation of these models are diverse. An example of difference in scope is shown in the fact that some models focus on assessing the user centredness of the organisation whereas others focus on measuring the user centredness of projects. Moreover, the existing UMM literature is focused on presenting the structure of the models and the methods for performing the assessment rather than presenting empirical evaluation of these models [1618. 


\section{Usability Maturity Models}

1. Nielsen Corporate Usability Maturity Model: Nielsen Corporate Usability Maturity Model [26] was developed in 2006 by Jackob Nielsen. It is composed of 8 stages or maturity levels. It declares that as organisations' usability matures they typically progress through the same sequence of stages from initial hostility to widespread reliance on user research [26].

2. Usability Maturity Model-Human Centredness Scale (UMM-HCS): UMM-HCS [8] was developed in 1998 by the European INUSE project that focused on the assurance of interactive systems or web sites usability. UMMHCS was derived from all significant existing UMMs. It embodies usability maturity via 6 maturity levels of a combination of attitude, technology, and management activities. UMM-HCS documentation includes an assessment recording form and its use is described [8].

3. Trillium: Trillium [4] is a process assessment approach for development of telecommunication products, developed in 1991 by Bell Canada. Trillium Model is based on (CMM) version 1.1. Although the model is extensively documented and published in the public domain, yet, it does not include methods on how to perform the assessment.

4. Usability Leadership Maturity Model (ULMM): Usability Leadership Maturity Model (ULMM) 1012 was developed by IBM in the early 1990s as a means of benchmarking and improving the status of usability in software development projects. It examines organisations from three different aspects: organisation, skills, and processes. The model documentation that is available in the public domain is very limited and only two papers are available [1012].

5. Humanware Process Improvement (HPI): Humanware Process Improvement was developed by Philips 1124]. HPI includes 10 Key Process Areas (KPAs) which identify UI design practices and suggest how these can be incorporated in the product creation process [11. HPI is based on the "Plan-Do-Check-Act" cycle and covers software and hardware aspects of products 24]. HPI provides a questionnaire as an assessment tool for self and full assessments [1].

6. User Centred Design Maturity (UCDM): User Centred Design Maturity (UCDM) 9] was developed at the University of Loughborough in the UK, initially as a tool for benchmarking information systems capability in the UK public sector. It has five capability areas, for example, "systems design", "project structure and goals" and maturity stages, and 15 foci of assessment [18].

7. Usability Maturity Model-Processes (UMM-P): UMM-P [7] was developed in the European INUSE project. It is intended to be used in the assessment and improvement of the human centred processes in system development. The model describes seven processes each defined by a set of base practices and associated work products. Examples of UMM-P processes are "Plan and manage the human-centred design process", and "Specify the user and organisational requirements". An assessment recording form is supplied and its use is described. 
8. KESSU: KESSU 20] is an assessment model that was developed in a national research project at Oulu University in Finland. The main selling point of KESUU is that it examines the performance rather than the management aspects of user centred processes. KESSU includes seven processes of UCD including: identify user, context of use, determine user requirements, produce user task designs, produce interaction designs, usability feedback and usability verification 18 .

9. Procedures for Usability Engineering Process Assessment (DATechUEPA): DATech-UEPA was developed in Germany. The model has one main focus of assessment (usability engineering) and identifies three levels of maturity and 19 foci of assessment. The model is tailored for the assessment of manufacturing organisations and is documented in German as cited in 18 .

10. Human Centred Design-Process Capability Model (HCD-PCM Design and Visioning): The HCD-PCM model was developed by Mitsubishi Research Institute, NTT Advanced Technology and Otaru University of Commerce in 2002. The model scope ranges over system life cycle processes such as processes from market visioning to system disposal process capability types. HCD-PCM model is composed of two models: one for visioning process and the other for design processes. The capability level for each of the visioning and the design process identifies five capability levels [18].

11. Open Source Usability Maturity Model (OS-UMM): OS-UMM [27] is a UMM for open source projects. It was developed by members from University of Western Ontario, Canada and Faculty of Information Technology, United Arab Emirates University. The OS-UMM model has five maturity levels. The proposed maturity scale has key usability factors, such as user requirements, user feedback, usability learning, user centred design methodologies, understandability, learnability, operability, attractiveness, usability bug reporting, usability testing, and documentation [27].

Table1provides a comparison for the maturity levels of the different UMMs. It indicates that the different UMMs vary in the number of maturity levels between eight (Nielsen Model) and three (DATech-UEPA).

\section{Criteria for Comparing Usability Maturity Models}

The following criteria were found relevant for the purposes of this work in order to compare the main characteristics of the different UMMs that are available in the public domain.

Lightweight: Since the chosen UMM will be utilized to assess the usability maturity level of each project, the model should be lightweight; it should require low overhead so as not to disrupt any Agile project schedule and low cost so as not to consume considerable time to perform the assessment or require additional personnel to conduct the assessment.

Detailed English Documentation: The model should provide detailed documentation that provides practitioners with detailed maturity model definition 
Table 1. Maturity Levels of Usability Maturity Models

\begin{tabular}{|c|c|c|c|c|c|c|c|c|}
\hline Nielsen & UMM-HCS & Trillium & UCDM & UMM-P & $\begin{array}{l}\text { DATech- } \\
\text { UEPA }\end{array}$ & \begin{tabular}{|l|} 
HCD- \\
PCM \\
Design
\end{tabular} & $\begin{array}{l}\text { HCD- } \\
\text { PCM } \\
\text { Vision- } \\
\text { ing }\end{array}$ & OS-UMM \\
\hline $\begin{array}{l}\text { Hostility } \\
\text { toward } \\
\text { usability }\end{array}$ & Unrecognised & Unstructure & 巴ncertainty & Incomplete & Introduced & Do & Awake & Preliminary \\
\hline $\begin{array}{l}\text { Developer- } \\
\text { centred } \\
\text { usability }\end{array}$ & Recognised & Repeatable & Awakening & Performed & $\begin{array}{l}\text { Reproducibl } \\
\text { Results }\end{array}$ & Plan & Know & Recognised \\
\hline $\begin{array}{l}\text { Skunk } \\
\text { works } \\
\text { usability }\end{array}$ & Considered & Defined & Enlightenmen & tManaged & $\begin{array}{l}\text { Continuous } \\
\text { Improve- } \\
\text { ment }\end{array}$ & Control & Understan & Defined \\
\hline \begin{tabular}{|l|} 
Dedicated \\
usability \\
budget
\end{tabular} & Implemented & Managed & Wisdom & Establisheф & $1-$ & Adapt & Infer & Streamlined \\
\hline $\begin{array}{l}\text { Managed } \\
\text { usability }\end{array}$ & Integrated & $\begin{array}{l}\text { Fully Inte- } \\
\text { grated }\end{array}$ & Certainty & Predictable & 5 & Optimiz & Create & Institutionalize \\
\hline $\begin{array}{l}\text { Systematio } \\
\text { usability } \\
\text { process }\end{array}$ & Institutionalize & 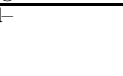 & - & Optimizins & 5 & - & - & - \\
\hline \begin{tabular}{|l|} 
Integrated \\
user- \\
centred \\
design \\
\end{tabular} & - & - & - & - & - & - & - & - \\
\hline $\begin{array}{l}\text { User- } \\
\text { driven } \\
\text { corpora- } \\
\text { tion } \\
\end{array}$ & - & - & - & - & - & - & - & - \\
\hline
\end{tabular}

and detailed descriptions of the assessment process. This detailed documentation will provide explicit guidance to practitioners to conduct self assessment, i.e., conduct the assessment on their own without the need for the presence of the model author. Moreover, since the available usability maturity/assessment models were developed in various countries, one of the criteria for choosing the usability maturity/assessment model is to be documented in English.

Domain Independent: Some UMMs are domain specific; i.e., they were created for specific domains like telecommunication or manufacturing. This implies that they focus on domain specific practices and cannot be utilized in other domains. Thus the model chosen should be domain independent; i.e., it should be suitable for utilisation in all organisations regardless of their domain of business.

Empirically Evaluated: The model should have been evaluated in empirical studies and iterated according to the results of these empirical evaluations.

The UMMs were examined using the criteria identified above and table 2 presents a summary of the results of the comparison between the different usability models according to the comparison criteria proposed earlier.

The UMM pursued is documented in English, has a detailed documentation, can be used irrespective of the organisation's domain (generic), is lightweight, and has been empirically evaluated.

These criteria led to the exclusion of a number of UMMs.

The language criteria led to the exclusion of DATech-UEPA, HCD-PCM Design and HCD-PCM Visioning since they were not documented in English. The detailed documentation criteria led to the exclusion of ULMM, HPI, UCDM, KESSU, and OS-UMM since they do not provide sufficient documentation to conduct the assessment in a self assessment form. However, this does not imply 
Table 2. Criteria for Choosing a Usability Maturity Model

\begin{tabular}{|c|c|c|c|c|c|}
\hline UMM Model & Language & \begin{tabular}{|l|} 
Detailed \\
Documenta- \\
tion
\end{tabular} & Domain & Lightweight & \begin{tabular}{|l} 
Empirical \\
Evaluation
\end{tabular} \\
\hline Nielsen & English & Yes & Generic & Yes & No \\
\hline UMM-HCS & English & Yes & Generic & Yes & Yes \\
\hline Trillium & English & Yes & Telecommunication & No & Not published \\
\hline ULMM & English & No & Generic & $\mathrm{N} / \mathrm{A}$ & Not Published \\
\hline HPI & English & No & $\begin{array}{l}\begin{array}{l}\text { Consumer Product } \\
\text { Development }\end{array} \\
\end{array}$ & N/A & Not Published \\
\hline UCDM & English & No & $\begin{array}{|lr|}\text { Information System } \\
\text { Capability in UK } \\
\text { Public Sector }\end{array}$ & $\mathrm{N} / \mathrm{A}$ & Not Published \\
\hline UMM-P & English & Yes & Generic & No & Yes \\
\hline KESSU & English & No & Generic & $\mathrm{N} / \mathrm{A}$ & Yes \\
\hline DATech-UEPA & German & $\mathrm{N} / \mathrm{A}$ & Manufacturing & $\mathrm{N} / \mathrm{A}$ & $\mathrm{N} / \mathrm{A}$ \\
\hline HCD-PCM Design & Japanese & $\mathrm{N} / \mathrm{A}$ & Generic & $\mathrm{N} / \mathrm{A}$ & $\mathrm{N} / \mathrm{A}$ \\
\hline HCD-PCM Visioning & Japanese & $\mathrm{N} / \mathrm{A}$ & Generic & $\mathrm{N} / \mathrm{A}$ & $\mathrm{N} / \mathrm{A}$ \\
\hline OS-UMM & English & No & Open Source Projects & $\mathrm{N} / \mathrm{A}$ & $\mathrm{N} / \mathrm{A}$ \\
\hline
\end{tabular}

that they did not have extensive documentation, for example, KESSU is published in numerous papers, however, all these papers and documentation provided a rather high level detail on the dimensions and processes rather than on the how to conduct the assessment. The domain criteria led to the exclusion of Trillium since it is domain specific as it is focused on the telecommunication industry. The lightweight criteria led to the exclusion of UMM-P since the model is not lightweight and requires considerable time to be conducted which may disrupt any Agile project schedule and impose considerable cost as a result of consuming considerable time to perform the assessment.

In case of the lack of enough documentation or the lack of English documentation, it was hard to judge whether the model is lightweight or not. As a result "Not Applicable (N/A)" was used as an indication that it was not applicable to make an evaluation.

This left us with only two UMMs: Nielsen Corporate Usability Maturity Model and Usability Maturity Model-Human Centrdness Scale. Although Nielsen model was not empirically evaluated, yet it was decided to utilise both models in five AUCDI case studies in order to provide richer comparative analysis via two UMMs.

\subsection{Choosing Five AUCDI Case Studies}

The second step of the research approach involved choosing five case studies that integrated Agile development processes and user centred design and represented successful and unsuccessful AUCDI attempts

A candidate list of five academic researchers and industrial practitioners were selected. This list included authors who developed new AUCDI approaches and whose work on AUCDI was well received and highly referenced. The chosen case studies also reflect a "two tail" design [29] in which cases from both extremes (success and failure) are selected. 
Interviewees were contacted via an email. All of the interviewees were professional usability practitioners whose job roles were: usability product manager, usability analyst, usability engineer, lead user experience designer, and team manager for user experience design. One interview was conducted per participant in which questions regarding Nielsen model were posed. At the beginning of the interview the interviewees were asked for their permission to record the interview and then the informed consent form was read and their consent on its terms was recorded. All interviewees agreed to record the interview. All interviews were transcribed in English. Each case study works in a different sort of software, however, all case studies implement Scrum. Four case studies represent successful integration attempts whereas one case study represent a failure integration attempt. The imbalance between the number of successful and unsuccessful case studies is attributed to the existence of publication bias since more positive results are published than negative results in the AUCDI domain as indicated by the results of a systematic literature review that was conducted on agile and user centred design integration [30].

For the sake of protecting the anonymity of participants, company names and some details on the projects will be withheld.

Case Study 1: The product developed in the first case study was a Software as a Service where high quality UX was crucial. The product developed an integration with a new ecommerce platform in order to allow sellers to sell their inventory to multiple ecommerce sites. The interviewee worked as a usability product manager, and was responsible for managing all the UX aspects of the project and designing the user interfaces. This project represented successful AUCDI attempt as declared by the author. This success occurred through utilising a variant of the Scrum methodology. The project had two peer product owners, one focused on usability and user experience and the other on the more conventional functions. The usability product owner took the lead in establishing a UX vision for the product along with a number of personas. The vision was realised in high level user goals, high level description of the UX with the product and a high level navigation model for the entire product.

Case Study 2: The second case study occurred at a leader company in the enterprise customer relationship management marketplace. The product developed was a second version of an approval process editor, the first version had very poor UX and users could not use the product as expected and there was poor adoption. Four years later it was subject to redesign. The interviewee worked as a usability analyst which involves being a dedicated UX researcher. This project represented successful AUCDI attempt as declared by the author. This occurred via first, introducing a new resource plan that reduced workload on UX team members and dedicated two hours per week by UX practitioners to assist Scrum teams that did not have assigned UX resources. Second, they introduced design transformations via moving to parallel development and design, working a release ahead, utilising interactive prototypes for usability testing, communication of designs to developers, and design studios. Third, using Rapid Iterative Test and Evaluation (RITE) for usability testing in all Agile projects. 
Case Study 3: The third case study occurred at a home shopping network company. The product developed was a new system that facilitates show planning for a home shopping network. Show planners used the software in order to schedule shows, products to shows and hosts to shows. The interviewee worked as a lead UX designer, running a team with three designers. This case study represented successful AUCDI attempt as declared by the author. This success occurred through the use of a rapid process that allows designers, developers, and stakeholders to collaborate and explore design alternatives. This occurred via some common guidelines where participants produce several rough sketch designs, then attended a collaborative workshop to discuss each other's work. This was followed by merging ideas to one design concept with which to move forward. This process reportedly had several advantages, for example, facilitating role sharing and knowledge transfer, allowing rapid exploration of design alternatives, and fostering shared understanding of design vision.

Case Study 4: The fourth case study occurred at a leading software and services company in the asset performance management domain. The product developed was a touch screen kiosk system for mechanics in order to receive work orders and record the results of the repair. The interviewee worked as a usability engineer. This case study represented successful AUCDI attempt as declared by the author. This success occurred through the use of a development approach that draws from extreme programming and scenario based design. This approach has two separate and synchronized usability and development tracks and the usability engineer works one iteration ahead of the developers. The key design is represented in a set of mock-ups, scenarios, claims, and design goals that were used to support synchronization activities and help the usability engineer plan and run usability evaluations.

Case Study 5: The fifth case study occurred at an Internet infrastructure services company that enable and protect interactions across the world's voice, video, and data networks. In addition to domain name registration and resolution. This company is a leading provider of security related products, for example, SSL certificates, identity and authentication services and enterprise security management. The product developed was a redesign of an existing web site for a product that allowed customers to purchase and manage services on-line. The goal of the project was to increase sales and customer retention, and reduce the number of support calls by providing an improved UX during the purchase and product renewal processes. The interviewee worked as a manager of UX design team which was a central team serving the whole company. This case study represented unsuccessful AUCDI attempt as stated by the author. At the end of the release the project went into the beta phase and a major problem was discovered since the users were unable to complete their purchase successfully. The product did not satisfy its requirements of increasing sales and improving customer retention. This resulted in pulling the software back in order to fix it. The cause of this failure was attributed to a lack of communication among the cross functional team members due to geographical separation and unwillingness by the engineering team to collaborate with non engineering teams and as a 
result the product manager and the UX team were prevented from participating in the sprint planning and Scrums. This led the engineering team to interpret and implement the designs incorrectly. There was also a lack of iterative refinement of designs.

\subsection{Utilising the Chosen UMM(s) in Five AUCDI Case Studies}

The fourth step of the research approach involved utilising the chosen $\mathrm{UMM}(\mathrm{s})$ (Nielsen Model) in assessing the usability maturity level of five case studies that integrated Agile development processes and user centred design and represented successful and unsuccessful AUCDI attempts. This occurred via conducting a set of one to one, Skype interviews. A set of open ended questions were formulated and posed to interviewees to evaluate the achievement of different practices. The questions were formulated in a manner that is precise, unambiguous, and understandable to respondents.

Answers to interview questions were used in evaluating the usability maturity level of each case study and the results of each case study were compared with the achieved practices in the different usability maturity levels in order to determine the closest usability maturity level. Those results are reported in section 5] in table 4 .

\subsection{Synthesizing the Results of Utilisation of UMMs}

The fifth step of the research approach involved synthesizing the results of utilisation of Nielsen Model in order to investigate the following: the existence of a relationship between the success of AUCDI attempts and usability maturity level and the suitability of UMMs for utilisation in assessing usability maturity in the context of Agile projects.

\section{Utilising Nielsen Corporate Usability Maturity Model in AUCDI Case Studies}

This section discusses the steps that were used in order to utilise Nielsen model in assessing the usability maturity level of the five AUCDI case studies introduced in section 3.2 .

Maturity models as a design product can take various forms including: pure textual description, functioning of the maturity model, or instantiation as a software assessment tool [25]. The Nielsen model is a textual model that is composed of 8 maturity levels but is written primarily as a textual narrative and this form cannot be easily deployed for measuring usability maturity of an organisation. Accordingly, the model was carefully examined in order to transform its narrative form into a set of measurable dimensions and practices. Each dimension is composed of a number of practices. This examination resulted in a model that is composed of five dimensions and 24 practices as shown in table 3 . These dimensions included: developers' attitude towards usability, management attitude 
towards usability, usability practitioners' role, usability methods and techniques, and strategic usability. Nielsen model describes each usability maturity level as a set of achieved practices. Thus 1 was used to signify an achieved practice and 0 was used to signify a non achieved practice in each usability maturity level. An identifier were given to each practice in order to assist with referring to it.

Table 3 reflects the dimensions, practices, and maturity levels involved in Nielsen model.

Table 3. Nielsen Corporate Usability Maturity Model Levels

\begin{tabular}{|c|c|c|c|c|c|c|c|}
\hline Dimension & Practices & ID & $125:$ & 345 & $5 \sqrt{6}$ & 7 & \\
\hline \multirow{3}{*}{ Developers Attitude Towards Usability } & Recognition of usability importance & A1.1 & 0.11 & & 11 & & 1 \\
\hline & $\begin{array}{l}\text { Recognition of importance of understand- } \\
\text { ing user needs }\end{array}$ & A 1.2 & & 1 & & & 1 \\
\hline & Developers not acting on behalf of users & A 1.3 & 0.01 & 1 & 11 & & 1 \\
\hline \multirow{4}{*}{ Management Attitude Towards Usability } & Recognition of usability importance & B1.1 & $0 \mid 1 / 1$ & 1 & 11 & & \\
\hline & Willingness to allocate funds for usability & B1.2 & $0: 0.1$ & 1 & $1 \mid 1$ & & 1 \\
\hline & Allocating funds for usability activities & B1.3 & 0.01 & 1 & 11 & & \\
\hline & $\begin{array}{l}\text { Presence of dedicated funds for usability } \\
\text { activities }\end{array}$ & B1.4 & 000 & 1 & & & 1 \\
\hline \multirow{2}{*}{ Usability Practitioners Role } & Presence of internal usability practitioner & C1.1 & 000 & 1 & & & \\
\hline & $\begin{array}{l}\text { Presence of a usability team led by a us- } \\
\text { ability manager }\end{array}$ & $\mathrm{C} 1.2$ & 000 & 0 & & & 1 \\
\hline \multirow{8}{*}{ Usability Methods and Techniques } & Performing usability testing & D1.1 & 0001 & 1 & & & \\
\hline & Planning for usability & D1.2 & $0|0| 0$ & $|1|$ & & & \\
\hline & Presence of a dedicated usability lab & D1.3 & 0.0 & 0 & 11 & & 1 \\
\hline & Utilising a usability reports archive to & $\mathrm{D} 1.4$ & $0: 0 \mid 0$ & 0 & $1 \mid 1$ & & \\
\hline & Performing early user research & D1.5 & 000 & 0 & $0 \mid 1$ & & 1 \\
\hline & Performing iterative design & D1.6 & 0.0 & 0 & 01 & & 1 \\
\hline & Quantitative usability metrics can be used & D1.7 & 0.00 & 0 & 0 & & 1 \\
\hline & $\begin{array}{l}\text { to track quality } \\
\text { Projects has defined usability goals }\end{array}$ & D1.8 & 00 & & & & 1 \\
\hline \multirow{7}{*}{ Strategic Usability } & $\begin{array}{l}\text { Presence of a tracking process for user } \\
\text { experience quality throughout design } \\
\text { projects and across releases }\end{array}$ & E1.1 & 000 & & & & \\
\hline & $\begin{array}{l}\text { Utilising user interface design standards } \\
\text { or a centralised definition of preferred de- } \\
\text { sign patterns }\end{array}$ & E1.2 & 000 & & & & 1 \\
\hline & $\begin{array}{l}\text { Projects are prioritised according to the } \\
\text { business value of their user experience }\end{array}$ & E1.3 & 0.00 & & & & \\
\hline & $\begin{array}{l}\text { Recognition of the need for user centred } \\
\text { design process }\end{array}$ & E1.4 & 0.00 & & & & \\
\hline & $\begin{array}{l}\text { Usability data is employed to determine } \\
\text { individual projects to be built }\end{array}$ & E1.5 & 0.00 & 0 & & & \\
\hline & $\begin{array}{l}\text { Concept of total user experience extend to } \\
\text { other forms of customer interaction with } \\
\text { the company }\end{array}$ & E1.6 & 0.00 & 0 & & & 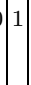 \\
\hline & $\begin{array}{l}\text { User research data is employed to deter- } \\
\text { mine overall direction and priorities }\end{array}$ & E1.7 & \begin{tabular}{l|l|l|l|l|l|l|l}
0 & 0
\end{tabular} & & & & \\
\hline
\end{tabular}

\section{Results}

This section reports on applying Nielsen Corporate Usability Maturity Model in the five AUCDI case studies that were discussed in section 3.2 and utilising the model in assessing their usability maturity level.

Interviewees from case study 1, 2, 3, 4, 5 are referred to as PT1, PT2, PT3, PT4, and PT5 respectively. In order to protect the anonymity of participants, 
Table 4. Case Study

\begin{tabular}{|c|c|c|c|c|c|c|c|}
\hline Dimension & Practices & ID & CS1 & CS2 & CS3 & CS4 & CS5 \\
\hline \multirow{4}{*}{ Developers Attitude Towards Usability } & Recognition of usability importance & A1.1 & 1 & 1 & 1 & 1 & 0 \\
\hline & Recognition of importance of under- & $\mathrm{A} 1.2$ & 1 & 1 & 1 & 1 & 0 \\
\hline & standing user needs & & & & & & \\
\hline & & & 1 & 1 & 1 & & \\
\hline \multirow{4}{*}{ Management Attitude Towards Usabilit } & Recognition of usability importance & B1.1 & 1 & 1 & t1 & 1 & 1 \\
\hline & Willingness to allocate funds for usabil- & B1.2 & 1 & 1 & 1 & 1 & 1 \\
\hline & $\begin{array}{l}\text { tiy activities } \\
\text { Allocating funds for usability activities }\end{array}$ & B1.3 & 1 & 1 & 1 & 1 & 1 \\
\hline & $\begin{array}{l}\text { Presence of dedicated funds for usabil- } \\
\text { ity activities }\end{array}$ & B1.4 & 1 & 1 & 0 & 1 & 1 \\
\hline \multirow[t]{2}{*}{ Usability Practitioners Role } & $\begin{array}{l}\text { Presence of internal usability practi- } \\
\text { tioner }\end{array}$ & C1.1 & 1 & 1 & 1 & 1 & 1 \\
\hline & $\begin{array}{l}\text { Presence of a usability team led by a } \\
\text { usability manager }\end{array}$ & C1.2 & 0 & 1 & 1 & 0 & 1 \\
\hline \multirow{8}{*}{ Usability Methods and Techniques } & Performing usability testing & D1.1 & 1 & 1 & 1 & 1 & 0 \\
\hline & Planning for usability & D1.2 & 1 & 1 & 1 & 1 & 1 \\
\hline & Presence of a dedicated usability lab & D1.3 & 0 & 1 & 0 & 0 & 1 \\
\hline & Utilising a usability reports archive to & D1.4 & 1 & 1 & 1 & 1 & 1 \\
\hline & Performing early user research & D1.5 & 1 & 1 & 1 & 1 & 1 \\
\hline & Performing iterative design & D1.6 & 1 & 1 & 1 & 1 & 0 \\
\hline & $\begin{array}{l}\text { Quantitative usability metrics can be } \\
\text { used to track quality }\end{array}$ & D1.7 & 1 & 0 & 1 & 1 & 0 \\
\hline & Projects has defined usability goals & D1.8 & 1 & 1 & 1 & 1 & 0 \\
\hline \multirow{7}{*}{ Strategic Usability } & $\begin{array}{l}\text { Presence of a tracking process for user } \\
\text { experience quality throughout design } \\
\text { projects and across releases }\end{array}$ & E1.1 & 0 & 1 & 0 & 0 & 0 \\
\hline & $\begin{array}{l}\text { Utilising user interface design standards } \\
\text { or a centralised definition of preferred } \\
\text { design patterns }\end{array}$ & E1.2 & 1 & 1 & 1 & 1 & 1 \\
\hline & $\begin{array}{l}\text { Projects are prioritised according to the } \\
\text { business value of their user experience }\end{array}$ & E1.3 & 0 & - & 0 & 0 & 0 \\
\hline & $\begin{array}{l}\text { Recognition of the need for user centred } \\
\text { design process }\end{array}$ & E1.4 & 1 & 1 & 1 & 1 & 1 \\
\hline & $\begin{array}{l}\text { Usability data is employed to determine } \\
\text { individual projects to be built }\end{array}$ & E1.5 & 1 & 1 & 1 & 1 & 1 \\
\hline & $\begin{array}{l}\text { Concept of total user experience extend } \\
\text { to other forms of customer interaction } \\
\text { with the company }\end{array}$ & E1.6 & 0 & 1 & 0 & 1 & 0 \\
\hline & $\begin{array}{l}\text { User research data is employed to de- } \\
\text { termine overall direction and priorities }\end{array}$ & E1.7 & 0 & 1 & 1 & 1 & 0 \\
\hline
\end{tabular}

the word "he" will be used to refer to all of them. Relevant interviewee quotes are included to illustrate the evaluations given to some of the assessed practices and these quotes are identified by the participant who said them. Case study 1 , 2, 3, 4 and 5 will be referred to as CS1, CS2, CS3, CS4, and CS5 respectively.

Table 4 reflects the results of applying Nielsen model on CS1, CS2, CS3, CS4, and CS5. The following section discusses the findings from applying Nielsen Corporate Usability Maturity Model in five AUCDI case studies.

\subsection{Maturity Level Evaluation of Case Studies via Nielsen Model}

Table 4 reflects the results of maturity level evaluation of Nielsen model for CS1, CS2, CS3, CS4, and CS5. Table 4, column CS1, CS2, CS3, and CS4 shows that the closest maturity level that describe CS1, CS2, CS3, and CS4 is maturity levels 7, 8, 7-8, and 8 respectively. However, column CS5 shows that CS5 differed significantly from all maturity levels. Thus it was given a maturity level of "Unknown".

The exploratory study that was conducted via Nielsen capability maturity model aimed to investigate the existence of a relationship between the success of 
AUCDI attempts and usability maturity level and the suitability of Nielsen Corporate Usability Maturity Model for utilisation in assessing usability maturity in the context of Agile projects.

\section{Aim 1: Investigating the existence of a relationship between the suc- cess of AUCDI attempts and usability maturity level}

This study revealed the existence of a correlation between the success of AUCDI attempts and AUCDI case study's usability maturity level. Successful AUCDI case studies all scored a usability maturity level that ranged from 7-8.

This result can have positive implications on AUCDI practice since practitioners who aim to achieve the integration can utilise Nielsen model before the start of their projects to assess their maturity level. In case of achieving a low maturity level then the different practices included in Nielsen model can be used as a checklist for areas that need to be improved.

It was not possible to determine the maturity level of CS5, an example of a failed AUCDI attempt as discussed in section 5.1 This was due to the wide difference between its achieved practices and any available maturity level. This difficulty of determining the maturity level of CS5 was due to the fact that it had low maturity for all practices related to developers' attitude dimension towards usability including: practice A1.1- "Recognition of usability importance", practice A1.2- "Recognition of importance of understanding user needs" and A1.3"Developers acting on behalf of users". However, it had high maturity for all practices related to the dimensions related to management attitude towards usability, usability practitioners role, usability methods and some practices related to strategic usability. Nevertheless, due to developers' attitude towards usability all the management awareness, allocated funds, usability practitioners and strategic usability practices were not effectively utilised. Moreover, the lack of cooperation of the development team led to discarding a number of practices including: practices- D1.1 "Performing usability testing", D1.6- "Performing iterative design", D1.7- "Quantitative usability metrics can be used to track quality", D1.8- "Projects has defined usability goals". The lack of communication among the cross functional team members due to geographical separation and unwillingness by the engineering team to collaborate with non engineering teams resulted in preventing the product manager and the user experience team from participating in the sprint planning and scrums. This led the engineering team to interpret and implement the designs incorrectly and resulted in lack of iterative refinement of designs.

This implies that the existence of management acknowledgment of usability importance and providing necessary infrastructure for usability activities , i.e., dedicated usability labs, usability professionals, usability funds, usability tools, etc are all less important to project success than developers' attitude towards usability and how they communicate with usability practitioners. 


\section{Aim 2: Investigating whether Nielsen Corporate Usability Maturity Model is suitable for utilisation in assessing usability maturity in the context of Agile projects}

Nielsen model was not initially developed for Agile software development processes, however, a number of criteria were set in order to investigate the suitability of Nielsen model for utilisation in assessing usability maturity in the context of Agile projects. These criteria involves the following:

\section{CR1: The usability maturity model should not conflict with Agile values and principles}

This criteria was set in order to maintain the agility of the development process in case of utilising Nielsen model. However, practice E1.1- "Presence of a tracking process for user experience quality throughout design projects and across releases" could pose a conflict with the Agile value of "Individuals and interactions over processes and tools". However, this practice also works in support of another Agile principle "Continuous attention to technical excellence and good design enhances agility" since the aim of practice E1.1 is to improve the quality of user experience across all products.

Thus it can be concluded that CR1 is satisfied by Nielsen model since the model does not conflict with Agile values and principles.

CR2: The usability maturity model should integrate UCD activities into the overall project plan and throughout the Agile development life cycle

The reason behind setting this criteria is that none of the major Agile processes explicitly include guidance for how to develop usable software [23. In addition, the interaction design role, usability, and user interface design in an Agile team is unclear and largely overlooked [53. Furthermore, principles and practices for understanding and eliciting usability and user requirements and evaluating Agile systems for usability and user experience are generally considerably deficient 2322 . In general, it is not yet clear how to incorporate UCD into Agile processes without sacrificing the acknowledged benefits of each of these individual processes.

As a result, criteria CR2 was considered as a significant factor for judging the suitability of Nielsen model for utilisation in assessing usability maturity in the context of Agile projects since the main problem that faces the Agile domain regarding the integration is when to perform the different UCD activities and how to make them more lightweight in order to accommodate the Agile processes iterative and incremental nature.

Nielsen model includes a variety of UCD activities embodied in the following practices

- D1.1- Performing usability testing.

- D1.2- Planning for usability.

- D1.4- Utilising a usability reports archive to compile past usability findings.

- D1.5- Performing early user research. 
- D1.6- Performing iterative design.

- D1.8- Projects has defined usability goals.

However, Nielsen model lacks details on the timing of applying practices D1.1, D1.2, D1.5, and D1.6. Although the model includes practice D1.2 that is focused on planning for usability, however no details were given on what this entails. Practice D1.2 does not clarify what is meant by planning for usability and whether it includes preparation for user research, usability testing or planning to integrate UCD activities into the software development life cycle or all of these issues collectively. Practice D1.4 is focused on utilising a usability reports archive to compile past usability findings, however, the practice does not discuss the form of this usability reports archive to clarify whether it is a lightweight or heavyweight form. Moreover, practice D1.4 focuses only on archiving (documenting) past usability findings without mentioning other aspects that are necessary for AUCDI and that need to be archived including: design rationale, source of requirements, results of user research, designs, expected delivery date of designs, etc that are all necessary in the context of Agile projects. Practice D1.5 is focused on performing early user research, however, it uses a generic term to refer to the timing of conducting user research (early), this can imply iteration 0 or sprint 0 in the Agile domain. Moreover, the practice is generic since it does not identify the activities that are involved in performing early user research including: identification of user groups, context of use, task analysis, etc. Practice D1.8 is focused on setting defined usability goals for projects yet the problem facing Agile teams is not to set usability goals but rather how to translate these goals into user stories or features in the product back log that can gain priority for execution in the tight Agile time lines and avoid marginalization.

Nielsen model is a generic model, i.e., it is not developed for a particular software development life cycle. As a result the model focus is on declaring the important practices for usability maturity rather than clarifying the timing, method or frequency for conducting these practices along the project plan or the phases of the product development life cycle. This is of specific importance in case of Agile development processes since significant part of the integration challenges are related to the iterative, incremental, tight time line nature of Agile development processes.

Thus it can be concluded that criteria CR1 is satisfied by Nielsen model since it does not conflict with Agile values and principle. However, criteria CR2 is not satisfied by Nielsen model since the model does not state clear timings and milestones along the Agile development life cycle for the inclusion of UCD activities into the overall project plan and all phases in the software development life cycle.

\section{Conclusion and Future Work}

This paper investigated the suitability of Nielsen Corporate Usability Maturity Model for utilisation in the Agile domain in order to assess the organisation's UCD capability. It reported on applying Nielsen Model in five case studies that 
integrated Agile development processes and user centred design and utilising the model in assessing their usability maturity level.

The investigation of the existence of a relationship between the success of AUCDI attempts and usability maturity level revealed the existence of a correlation between the success of AUCDI attempts and the AUCDI case study's usability maturity level since successful AUCDI case studies all scored a usability maturity level that ranged from 7-8. Whereas, with the failed AUCDI attempt, it was not possible to determine its maturity level and as a result it was given a maturity level of "Unknown".

Moreover, the investigation of the suitability of UMMs for utilisation in assessing usability maturity in the context of Agile projects gave an indication that the model does not conflict with Agile values and principles. However, although the model includes a variety of UCD activities, yet, it lacks details on the timing of applying the different practices along the Agile development life cycle iterations or sprints. This is of specific importance in case of Agile development processes as significant part of the integration challenges that faces Agile projects is related to the timing of performing the different UCD activities in order to accommodate the Agile processes' iterative and incremental nature.

Although the existence of a correlation between the success of AUCDI attempts and the AUCDI case study's usability maturity level result can have positive implications on AUCDI practice since practitioners who aim to achieve the integration can utilise Nielsen model before the start of their projects to assess their maturity level. In case of achieving a low maturity level then the different practices included in Nielsen model can be used as a checklist for areas that need to be improved. However, two issues are of concern: first, Nielsen model is a descriptive maturity model, thus it is limited to acting as a diagnostic tool rather than an improvement tool, so the model can assess the performance and pinpoint weak areas but the procedures of improvement of these areas are left to practitioners and are not tackled by the model. Second, the lack of timing for the different UCD activities can hinder the usefulness of the model since organisations can use it as a checklist of the UCD activities that need to be performed, however, when they initiate their software development process they will be more concerned with the timing and the lightweight method through which they can achieve the recommended UCD activities by Nielsen model.

Moreover, an open issue is the further AUCDI challenges that are specific to the Agile domain and that are not tackled in Nielsen model. These issues need to be taken into consideration by any researcher who considers developing a UMM in the context of Agile projects. AUCDI challenges that are not approached by Nielsen model are: practices regarding the communication, coordination and collaboration between UCD practitioners and Agile developers in order to synchronize and complete their work, practices related to design modularization and chunking, UCD practitioner workload, and maintaining communication between the customer and the development team 30. Moreover, another issue that needs to be approached by the developers of UMMs for Agile development processes 
is the features and activities that should be played by some team roles including $\mathrm{XP}$ coach, and scrum master whose role can impact the integration process.

Future work will involve applying UMM-HCS model in the same five case studies that integrated Agile development processes and UCD and utilising the model in assessing their usability maturity level.

\section{References}

1. Beck, K.: Manifesto for Agile Software Developement (2000)

2. Blomkvist, S.: Towards a Model for Bridging Agile Development and User-Centered Design. In: Seffah, A., Gulliksen, J., Desmarais, M. (eds.) Human-Centered Software Engineering - Integrating Usability in the Software Development Lifecycle. Human-Computer Interaction Series, vol. 8, pp. 219-244. Springer Netherlands (2005)

3. Beyer, H., Holtzblatt, K., Baker, L.: An Agile Customer-Centered Method: Rapid Contextual Design. In: XP/AU (2004)

4. Coallier, F.: TRILLIUM: A Model for the Assessment of Telecom Product Development \& Support Capability. Software Process Newsletter 2, 13-18 (1995)

5. Constantine, L.: Process Agility and Software Usability: Towards Lightweight Usage Centred Design (2001b)

6. Detweiler, M.: Managing UCD within Agile Projects. Interactions 14(3), 40-42 (2007)

7. Earthy, J.: Usability Maturity Model: Processes Version 2.3. Technical report, Llyod's Register, 71Fenchurch St, London,EC3M 4BS (2011)

8. Earthy, J.: Usability Maturity Model: Human Centredness Scale:INUSE Project Deliverable D5.1.4 (s) Version 1.2. Technical report, Llyod's Register, 71Fenchurch St, London,EC3M 4BS (1998)

9. Eason, Haker: User Centred Design Maturity. Internal Working Document. Technical report, Department of Human Sciences. Loughborough University (1997)

10. Flanagan, G., Rauch, T.: Usability Management Maturity, Part 1: Self Assessment: How Do You Stack Up? In: CHI 1995 Conference Companion (4) (1995)

11. Gupta, A.: Humanware Process Improvement Framework: Interfacing User Centred Design and the Product Creation Process at Philips. Position Paper Delivered at Human Centred Process Improvement Group (HCPIG) Meeting.Teddington, UK (1997)

12. Rauch, T., Flanagan, G.: Usability Management Maturity, Part 2: Usability Techniques - What Can You Do. In: CHI 1995 Conference Companion (1995)

13. Fowler, M.: The New Methodology (December 2005)

14. Gottschalk, P.: Maturity Levels for Interoperability in Digital Government. Government Information Quarterly 26, 75-81 (2009)

15. Gould, J., Lewis, C.: Designing for Usability: Key Principles and What Designers Think. Communications of ACM 28(3), 300-311 (1985)

16. Iivari, N., Jokela, T.: Evaluating a Usability Capability Assessment. In: Bomarius, F., Komi-Sirviö, S. (eds.) PROFES 2001. LNCS, vol. 2188, pp. 98-109. Springer, Heidelberg (2001)

17. Iversen, J., Nielsen, P.A., Norbjerg, J.: Situated Assessment of Problems in Software Development. ACM SIGMIS Database - Special Issue on Infomration Systems 30(2), 66-81 (1999) 
18. Jokela, T., Siponen, M., Hirasawa, N., Earthy, J.: A Survey of Usability Capability Maturity Models: Implications for Practice and Research. Behaviour and Information Technology 25(3), 263-282 (2006)

19. Jokela, T., Abrahamsson, P.: Usability Assessment of an Extreme Programming Project: Close Co-operation with the Customer Does Not Equal to Good Usability. In: Bomarius, F., Iida, H. (eds.) PROFES 2004. LNCS, vol. 3009, pp. 393-407. Springer, Heidelberg (2004)

20. Jokela, T.: An Assessment Approach for User-Centred Design Processes. In: EUROSPI. Limerick Institute of Technology Press, Limerick (2001)

21. Jokela, T., Abrahamsson, P.: Modelling Usability Capability - Introducing the Dimensions. In: Bomarius, F., Oivo, M. (eds.) PROFES 2000. LNCS, vol. 1840, pp. 73-87. Springer, Heidelberg (2000)

22. Kane, D.: Finding a Place for Discount Usability Engineering in Agile Development: Throwing Down the Gauntlet. In: Proceedings of the Conference on Agile Development, ADC 2003. IEEE Computer Society, Washington, DC (2003)

23. Lee, J.C., McCrickard, S., Stevens, T.: Examining the Foundations of Agile Usability with eXtreme Scenario-Based Design. In: Agile Conference, pp. 3-10 (August 2009)

24. McClelland, I., Gelderen, T., Taylor, B., Hefley, B., Gupta, A.: Humanware Process Improvement - Institutionalising the Principles of User Centred Design

25. Mettler, T.: Maturity Assessment Models: A Design Science Research Approach. International Journal of Society Systems Science 3, 81-98 (2011)

26. Nielsen, J.: Jakon Neilsen's Alertbox: Corporate Usability Maturity:Stages, pp. 1-4 (2006)

27. Raza, A., Capretz, L.-F., Ahmed, F.: An Open Source Usability Maturity Model (OS-UMM). Computers in Human Behavior 28(4), 1109-1121 (2012)

28. Rosemann, M., de Bruin, T.: Towards a Business Process Management Maturity Model. In: European Conference on Information Systems, Regensburg. Germany (2005)

29. Yin, R.: Case Study Research: Design and Methods. Sage, Beverly Hills (2009)

30. Salah, D., Paige, R.F., Cairns, P.: A systematic literature review for agile development processes and user centred design integration. In: Proceedings of the 18th International Conference on Evaluation and Assessment in Software Engineering (EASE 2014), Article 5 , 10 pages. ACM, New York (2014), http://doi.acm.org/10.1145/2601248.2601276, doi:10.1145/2601248.2601276 